\title{
Subacute and Chronic Treatment with Herbal Medicine Essential Oil the Alpinia Zerumbet Associated with Kinesiotherapy on Patient with Muscle Spasticity: Cases Series
}

\author{
Janaína Farias Cândido ${ }^{1,2}$, Drielly Catarinny dos Santos Meneses ${ }^{1,2}$, José Nolasco de Carvalho- \\ Neto $^{3}$, Lauro Xavier-Filho ${ }^{4}$, Edna Aragão Farias Cândido ${ }^{* 1,2,4}$ \\ ${ }^{I}$ Laboratory of Biological Studies and Natural Products, Research and Technology Institute (RTI), Aracaju/SE - \\ Brazil \\ ${ }^{2}$ Postgraduate in Health and Environment.Tiradentes University (UNIT), Aracaju/SE - Brazil. \\ ${ }^{3}$ Department of Medicine. Federal University of Sergipe \\ ${ }^{4}$ Northeast Network of Biotechnology (Renorbio)
}

*Corresponding Author: Edna Aragão Farias Cândido, Laboratory of Biological Studies and Natural Products, Research and Technology Institute (RTI), Aracaju/SE - Brazil, ${ }^{2}$ Postgraduate in Health and Environment.Tiradentes University (UNIT), Aracaju/SE - Brazil, ${ }^{4}$ Northeast Network of Biotechnology (Renorbio)

\begin{abstract}
:
Purpose: The goal of this study was to assessment subacute and chronic treatment with herbal medicine OEAz associated with Kinesiotherapy on patient with muscle spasticity: cases series.

Methods: It is a monocentric study for convenience and prospective with different treatment periods in subacute and chronic treatments in two (2), three (3), four (4), five (5), six (6) and seven (7) months by intradermal in the doses of $0.05 \mathrm{mg} / 2 \mathrm{Kg}$ in tetraparetic and $0.05 \mathrm{mg} / 4 \mathrm{Kg}$ in hemiparetic. Spasticity scores were measured by the Ashworth modify scale. Wilcoxon, Kruskal-Wallis test were used for significant results of $p<0.05$.
\end{abstract}

Results: In child, teenagers and adults were observed a significant $p<0.05$ spasticity decrease when treated with herbalmedicine OEAz associated with Kinesiotherapy, in different periods, been the results more expressive in 7 months.

Conclusion: herbal medicine OEAz associated with Kinesiotherapy revealed an effective intervention strategy for chronic treatment of spastic muscle.

Keywords: Alpinia; essential oil; physiotherapy; muscle spasticity; phytotherapy

Abbreviations: Central Nervous System (CNS), Pyramidal Syndrome (SP), L type voltage gated $\mathrm{Ca}^{2+}$ channel (L-type Ca2+), Essential oil the Alpinia zerumbet (OEAz), Modified Modified Ashworth Scale (MMAS)

\section{INTRODUCTION}

Central Nervous System when injured could induce movement disorders, tonus and posture. In child, this alteration affects motor development, leading to abnormal postures and movement patterns in the CNS maturation period, mostly on first two years of life (1), known as SP. Although there are no genetic component, not yet comprehensive neurologic influence shows aberrant forms of genetic expression (2). However, Pingel et al.(3) evidence there are many factors that influence the muscles from this lesion being contracted, citing changes of cellular homeostasis mechanisms, genetics and epigenetics.

Smith et al. (4) relates L-type Ca2+ with increased genetic expression, besides other muscle proteins like parvalbumin, calsequestrin, triadine, calmodulin and phosphatase 3 protein, calmodulin calcium dependent. As L-type Ca2+ are also altered on medullar motoneurons, according to Bennet et al. (5), justifying the peripheral neuronal hyperactivity. These altered genetic expression result in a change of myosin heavy chain and consequently inadequate contraction (6).

As much Smith et al. (4), as Pingel et al. (3) assert the involvement of this alterations in the central lesions muscle commitment context, Smith et al. (4) describe one of these alterations be a possible therapeutic aim, mentioning the L-type $\mathrm{Ca} 2+$. 
Santos et al. (7) and Maia et al. (8) referenced OEAz chromatographic characteristics the herbal medicine with OEAz, used in this present study, as abundant in monoterpenes, terpinen-4-ol (37.62\%), 1,8-cineole (17.58\%), gamma terpene $(11.77 \%)$ and para-cymene $(10.67 \%)$. In your studies, Santos et al. (7) demonstrate that OEAz the herbal medicine OEAz modulated by dose dependent way the L-type Ca2+. Since 2006, OEAz has been investigated in spasticity modulation action with functional motor system gain in spasticity acute treatment $(9 ; 10 ; 8)$.

The goal of this study was to assessment subacute and chronic treatment with herbal medicine $\mathrm{OEAz}$ associated with Kinesiotherapy on patient with muscle spasticity: cases series.

\section{Materials AND MethodS}

\subsection{Study Design and Participants}

This research is about clinical cases study, monocentric, prospective, for convenience, cases series divided in child, teenagers and adults treated in specific periods, in subacute and chronic forms where the spasticity was the variant.

This work complies with the principles laid down in the Declaration of Helsinki 2013, recommendations guiding physicians in biomedical research involving human subjects, and was approved by the local Committee on Ethics in Research with Human Beings (CAAE- \# 56717516.1.0000.53).Activities were started after research project submission and respective approval by Ethics Committee. The selected volunteers were informed about study methodology, propose and consulted about participation interest. After read and having agreement, free informed consent form was signed.

\subsection{Drug Treatment}

The treatment was carried out with Alpinia zerumbet essential oil extracted by steam trawl and diluted in vegetable oil (33\%). In cases of tetraparetic and hemiparetic commitment the doses were $0.05 \mathrm{mg} /$ $2 \mathrm{Kg}$ in and $0.05 \mathrm{mg} / 4 \mathrm{Kg}$, respectively. The medication application site was the spasticity muscle, having the total dose per individual divided by these commitment muscles quantitative.

\subsection{Procedures}

Study groups were divided in subacute (from 11 to 35 applications; equivalent) and chronic (from 36 to 72 applications), to better evaluate medical effects in time line witch was measured in months, two (2) to six (6).

Duration treatment was equivalent to 1 hour, in alternate days of Kinesiotherapy associated to herbal medicine OEAz application. Exercise consisted in assisted axial, scapular and pelvic to dissociate waists to control movement exercise, appendicular selective movements exercise, and closed chain to get up from sitting, step and inverted bicycle exercise, for adults; or Kinesiotherapy for children (9).

Inclusions criteria was paresis and plegia associated with muscle spasticity due to Pyramidal Syndrome. Patient with dermatitis, dermic allergy and blood pressure of 100/60 $\mathrm{mmHg}$ were excluded, and witch did not agree to participate of the study.

Tonus evaluation was by a MMAS (11) following the guidelines. The value, before and after the treatment following guidelines were: patient in supine and relaxed. Muscles were shortened and distended in maximum way in one (1) second. Scores punctuation was: $0=$ None muscle tonus increase; $1=$ Slightly muscle tonus increase, manifested as minimum resistance at the wide movement end, when the affected part is moved in flexion or extension; $1+=$ Slightly muscle tonus increase, manifested as minimum resistance at the remaining movement amplitude, but the affected part (s) is (are) easily moved; 2 = More evident muscle tonus increase, manifested as most movement amplitude, however easily moved; $3=$ Considered muscle tonus increase with hard passive movement during entire movement amplitude; and $4=$ affected parts rigid in flexion or extension.

\subsection{Statistical Analysis}

Kolmogorov-Smirnov test was utilized to analyses studies variable normality. Groups presented in supposition of non-satisfactory normality, applying Wilcoxon Marched Pairs test for dependent paired groups and Kruskal-Wallis with Dunn's post test for three more groups. In every analyzes Ashworth scores were adjusting in numeric sequence due to $1+$ that become 2 and successively the others scores, besides the significant level of $5 \%$ be considered. 


\section{RESULTS AND DISCUSSION}

The results refer to tonus decrease of spastic patient treated with herbal medicine OEAz. Treatment time differed in two (2), three (3) four (4), five (5), six (6) and seven (7) months with propose of verify response to subacute and chronic treatment. Besides treatment pause for 6 months in a condition of 1, 2 months' treatment and condition of 7 months' treatment following by 6 months without treatment and after more 7 years without treatment (Figure 1 A, B, C, D, E, F, G e H). The child had Cerebral Paralysis clinical diagnosis and adults stoke.

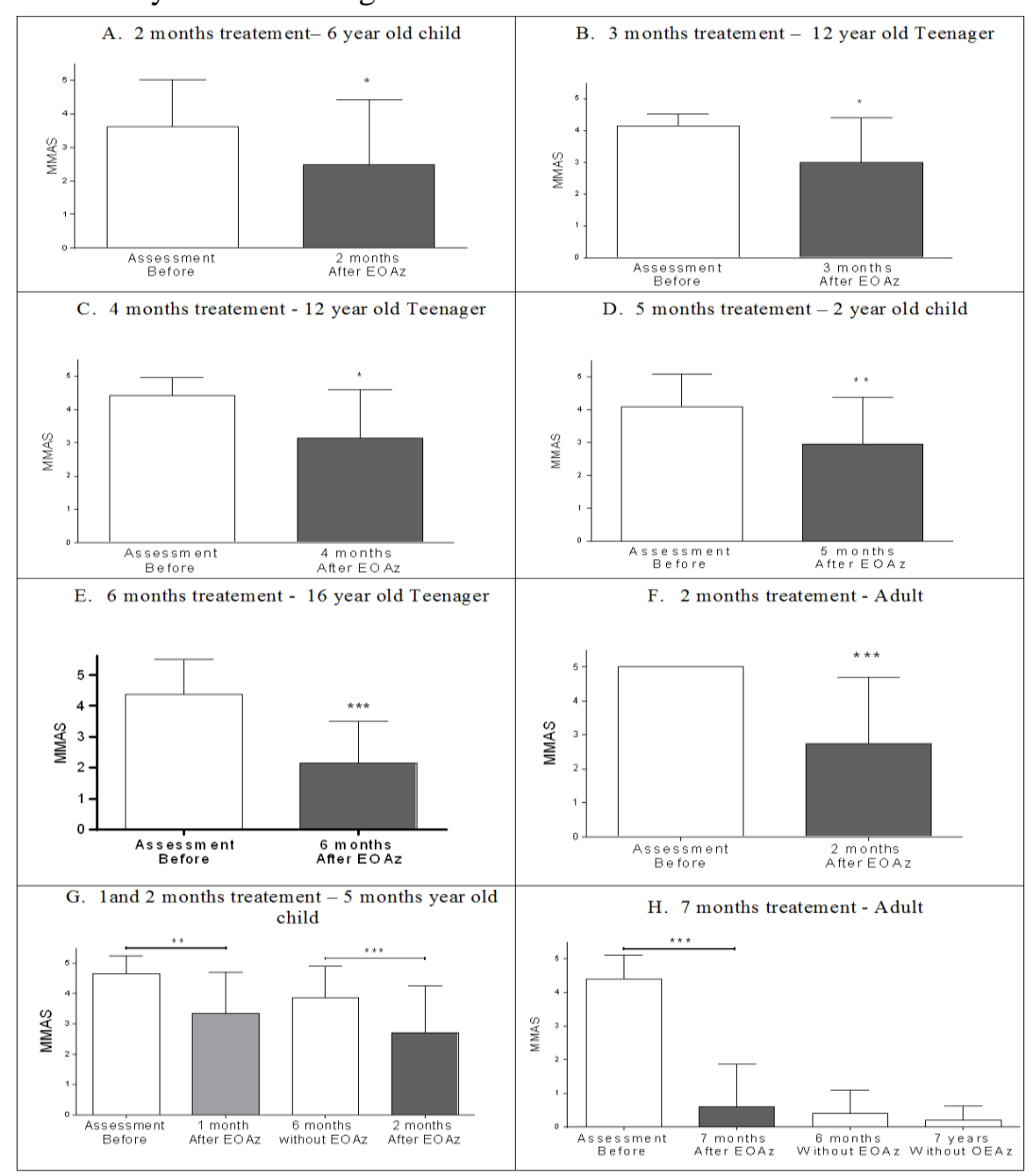

Figure1. Spasticity comportment by Modified Modified Ashworth Scale (MMAS) in adults with stroke and Cerebral Paralysis children OEAz treated subacutely and chronically $(0.05 \mathrm{mg} / 2 \mathrm{Kg}$; $0.05 \mathrm{mg} / 4 \mathrm{Kg}$ dose; tetraplegic and hemiplegic). Wilcoxon test was applied to measure before and after treatment; and KruskalWallis test with Dunn's post test to compare time treatment and no time treatment; $* p<0.05 ; * * p<0.01$ and $* * * p<0.001$

In 1A figure, a 6 years old child volunteer was treated subacutely with $0.6 \mathrm{~mL}$ dose per 2 months' treatment getting significant tonic decrease in relation to treatment beginning $(p<0.05)$.In $1 \mathrm{~B}$ and $1 \mathrm{C}$ figure, the following results are from a 12 years old patient treated chronically with herbal medicine OEAz $(0.5 \mathrm{~mL})$ for 3 months, significant difference $(p<0.01)$. When treated during for 4 months, also demonstrated significant relaxation $(p<0.01)$. Time without treatment was 1 month, reason why the results are separated. In 1D figure, results from 2 years old child treated with $0.5 \mathrm{~mL}$ dose for 5 months, it was obtained a significant result $(\mathrm{p}=0.049)$. In $1 \mathrm{E}$ figure, the 16 years old teenager treated chronically with a $2.3 \mathrm{ml}$ dose for 6 months presented significant results $(p<0.001)$.Figure 1F, hemiparetic adult treated for 2 months with $0.6 \mathrm{~mL}$ dose in spastic muscle. Results were also favorable revealing significant spasticity decrease after the treatment period $(\mathrm{p}<0.001)$. Whereas the $1 \mathrm{G}$ figure refers to a patient treated with herbal medicine $\mathrm{OEAz}$ with time intervals without treatment. Child was 5 months' years old and when treated with $0.5 \mathrm{~mL}$ dose demonstrated significant tonic modulation in 1 month $(p<0.01)$ and 2 months $(p<0.001)$. However, when had a period without 
treatment, the hypertonic scores increase being the same as the $1^{\mathrm{a}}$ evaluation. Lastly, on $1 \mathrm{H}$ figure, the patient was a 29 years old adult treated chronically with $1.3 \mathrm{~mL}$ dose during 7 months. Treatment results came up significant $(\mathrm{p}<0.001)$ regarding hypertonia before treatment. After 6 months without treatment, when being evaluate, was observed that muscle relaxation continues, because did not have significant difference from after treatment tonic evaluation. After 7 years, it still has no spasticity.

On Figure 2 behavior over time and how spasticity presented its scores was demonstrated, before and after treatment. Every patient results were; regardless of age, severity at the start of treatment or cause of spasticity; evaluated separately by treatment time. Both mean and median demonstrated that the patients still have moderate spasticity, except an adult patient treated for 7 months. However, with expressive significant decrease of spasticity, the longest time regarding the others.
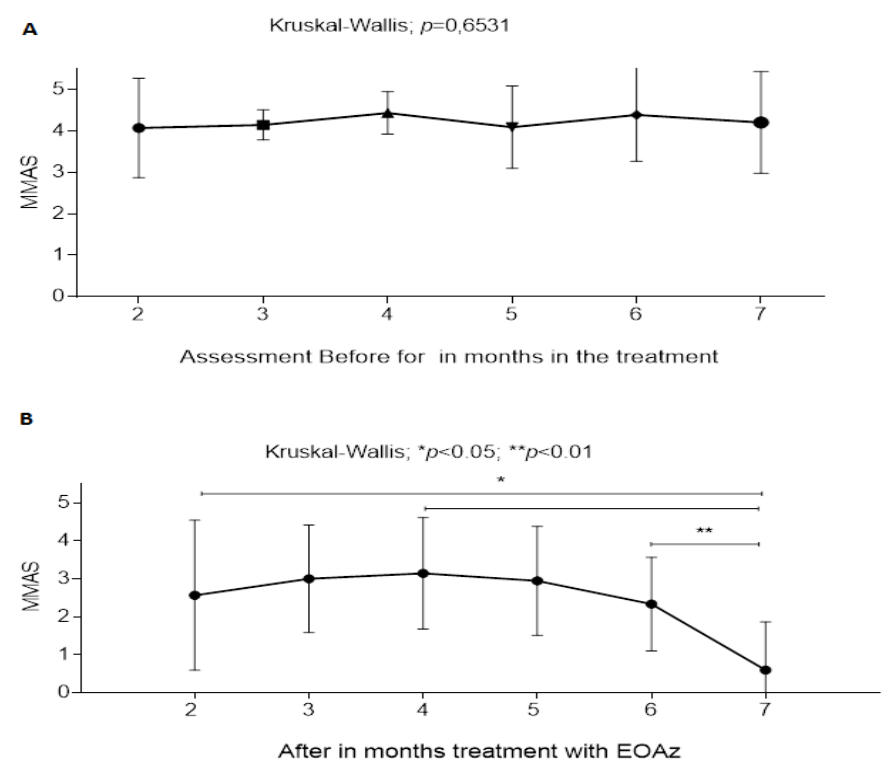

Figure2. $2 A$ figure presents the initials scores and $2 B$ figure the finals scores times treatment by Modified Modified Ashworth Scale (MMAS) according with corporal topographic and ages. Kruskal-Wallis test with Dunn's post test for compare final treatment results * $p<0.05 ; * * p<0.01$ and $* * * p<0.001$

On figure 3, spasticity scores after treatment were compare to bigger or smaller time treatment; taking the stratification in 5 months and 2 years old child (A), 6 to 16 years old child (B) and adult (C) into consideration treated for 7 months. Comparison were made after treatment. It was verifying significant spasticity decrease only in adults $(p=0.03)$. Although 6 to 16 years old child time be bigger than adults, it did not show significant difference between post treatment results, and in youngers child (5 months and 2 years) spasticity scores decreased, nevertheless with no significance.

Results obtained from this study demonstrate that both subacute and chronic herbal medicine OEAz treatment decrease hypertonia significantly.

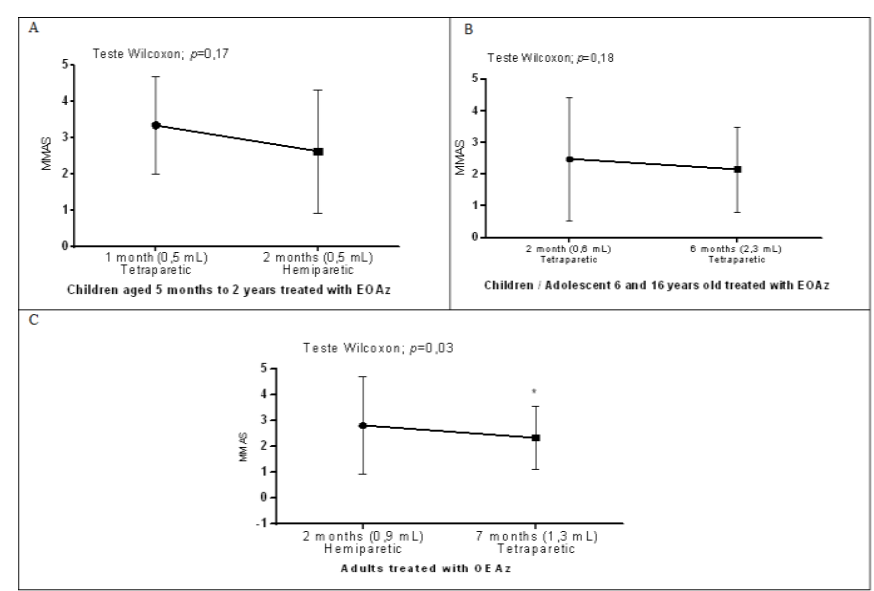

Figure3. Spasticity inhibition comparison group by Ashworth Scale post chronic treatment. Wilcoxon test was applied to measure before and after treatment; * $p<0.05 ; * * p<0.01$ and $* * * p<0.001$ 
Topic application is justified on the study basis of Cal (12) that presented, in vitro, better option in relation to others four terpenes types, besides better results in oil solution to hydrogel emulsion utilization, to be used as vehicles. Terpenes absorption read was realized at least 1 hour after its application, and its tissue absorption is from 10 to 20\%. This application time and pharmacokinetics activity are also according to Khalil et al.(13). Another justification given by the present study is that dermal application is easy to be topic, thus, directing the bioproduct on hyperactivity compromised muscleL-type $\mathrm{Ca} 2+$ (spastic).

In research, Santos et al.(7) verify that OEAz (100\%), same as utilized on Zicague ${ }^{\circledR}$ this study, significantly fast reduced L-type Ca2+, reversible and contraction dependent ( 25 and $250 \mu \mathrm{g} / \mathrm{mL}$; $p<0.05$ ); thus justify, spasticity inhibition results obtained in every present study related case.

L-type $\mathrm{Ca} 2+$ was recognized as altered in spastic muscle $(4,14,15)$ and are responsible for passive tension that directly induce spasticity (16) besides increase muscle stiffness (17). Muscle stiffness is pointed as increase spasticity cause (6).Therefore, Cerqueira et al. (10) evidenced that OEAz, Dosed oil, was capable to revert collagen thickness and organization alteration in rats' subacute treatment (45 days of treatment) with spastic spine cord injury.

The muscular weakness as it relates to stroke, is closely connected to inability and dependence. The should be applied activity in association to resisted, including aerobic exercise, functional training and supervised (18). However, should be care fulling in cases of central lesion patients, because abnormal tonic reactions can be reinforcing on them and consequently increase spasticity. Justifying, therefore, Kinesiotherapy limitations on spastic individuals' treatment with for muscle strength goal.

For Cândido and Xavier-Filho(9), Kinesiotherapy associate with OEAz, Dosed oil, acute treatment (1 month), in same dose as utilized in this study, also dermal applied in Cerebral Paralysis child, present significant effective results in spasticity decrease and functional gain.

Even though it is already significantly, before and after treatment comparison, was noticed that after 6 months' treatment, the post treatment results, compared to each other, presents bigger spasticity scores decrease in relation to shorter treatment time. However, with 7 months had significant difference even bigger on spasticity decrease in relation to treatment second $\left(2^{\circ}\right)$, third $\left(3^{\circ}\right)$, fourth $\left(4^{\circ}\right)$ and fifth $\left(5^{\circ}\right)$ month.

\section{CONCLUSIONS}

The herbal medicine OEAz associated with Kinesiotherapy in different treatment times provided significant spasticity decrease, probably by L-type $\mathrm{Ca} 2+$ modulation. Also, 7 months and longer time be the most appropriate to better spasticity control, after longer treatment pause. It is necessary to continue researches, increase number of individuals treated for 7 months to verify repeat response founded in the present study.

\section{REFERENCES}

[1] Mcintyre S, Taitz D, Keogh J, Goldsmith S, Badawi N, Blair E. A systematic review of risk factors for cerebral palsy in children born at term in developed countries. Develop Med \& Chil Neurol. 55(6):499_508 (2013).

[2] Smith LR, Chambers HG, Subramaniam S, Lieber RL. Transcriptional abnormalities of hamstring muscle contractures in children with cerebral palsy. PloS One. 7(8):1-13 (2012).

[3] Pingel J; Bartels EM; Nielsen JB. New perspectives on the development of muscle contracture following central motor lesions. The J Physiol. 595(15):1027-1038 (2016).

[4] Smith LR, Póten E, Hedstrom Y, Ward SR, Chambers HG, SubramaniamS.Novel transcriptional profile in wrist muscles from cerebral palsy patients. BMC Med Genom. 2(44):1-16 (2009).

[5] Bennet DJ, Sanelli L, Cooke CL, Harvey PJ, Gorassini MA.Spastic longlasting reflexes in the awake rat after sacral spinal cord injury.J Neurop. 91(5):2247-2258 (2004).

[6] Mathewson MA, Ward SR, Chambers HG, Lieber RL. High resolution muscle measurements provide insights into equinus contractures in patients with cerebral palsy. Journal of orthopaedic research: official publication of the Orth Res Soc. 33(1):33-39 (2015).

[7] Santos BA, Roman-Campos D, Carvalho MS, Miranda FMF, Carneiro DC, Cândido EAF, Filho LX, Cruz JS, Gondim NA.Cardiodepressive effect elicited by the essential oil of Alpinia speciosa is related to L-type Ca2+ current blockade. Phytom., 18(7):539-543 (2011).

[8] Maia MON, Dantas CG, Xaxier-Filho L, Cândido EAF, Gomes MZ. The Effect of Alpinia zerumbet Essential Oil on Post-Stroke Muscle Spasticity. Bas\&ClinPharmac\&Toxic. 118:58-62 (2016). 
[9] Cândido EAF, Xavier-Filho L.Viabilidade do uso do óleo essencial da Alpinia zerumbet, Zingiberaceae, na otimização do tratamento fisioterapêutico em paralisia cerebral espástica.Arq Bras Neur. 31:110-115 (2012).

[10] Cerqueira FL, Albuquerque-Junior RLC, Zini CA, Caramao EB, Cândido EAF. Efeitos da cinesioterapia associada ao bioproduto à base do óleo essencial da Alpinia zerumbet sobre o colágeno dos tecidos musculares espásticos de ratos pós-lesão medular. InterSciencePlace - Rev Cient Intern. 10(4):127-206 (2015).

[11] Ansari NN, Naghdi S, Younesian P, Shayeghan M. Inter- and intrarater reliability of the Modified Modified Ashworth Scale in patients with knee extensor poststroke spasticity. Physiot Teor Prac. 24:205213 (2008).

[12] Cal K. How does the type of vehicle influence the in vitro skin absorption and elimination kinetics of terpenes? Arch of Dermatol Res.297:311-315 (2006).

[13] Khalil Z, Pearce AL, Satkunanathan N, Storer E, Finlay-Jones JJ, Hart PH. Regulation of Wheal and Flare by Tea Tree Oil: Complementary Human and Rodent Studies. J of Invest Dermatol. 123(4):683-690 (2004).

[14] Smith LR, Lee KS, Ward SR, Chambers HG, Lieber RL.Hamstring contractures in children with spastic cerebral palsy result from a sitiffer extracellular matrix and increased in vivo sarcomere length. J Physiol. 589(10):2625-2639 (2011).

[15] Smith L.R.; Chambers H.G.; Lieber R.L. Reduced satellite cell population may lead to contractures in children with cerebral palsy. Develop Med \& ChildNeurol. 55(3):264-270 (2013)

[16] Roy A, Krebs HI, Bever CT, Forrester LW, Macko RF, Hogan N. Measurement of passive ankle stiffness in subjects with chronic hemiparesis using a novel ankle robot. J Neuro. 105(5):2132-2149 (2011).

[17] Neagoe C; Opitz C A; Makarenko I; Linke WA. Gigantic variety: expression patterns of titin isoforms in striated muscles and consequences for myofibrillar passive stiffness. J of Musc Res \& Cel Mot. 24(23):175-189 (2003).

[18] Borges CAS, Castão KC; Souto PA, Zan TB; Pompeu JE, Fukuda TY. Effect of Resisted Exercise on Muscular Strength, Spasticity and Functionality in Chronic Hemiparetic Subjects: A Systematic Review. The J of Appl Res. 9(4):147-158 (2009).

Citation: J. Farias Cândido et al., "Subacute and Chronic Treatment with Herbal Medicine Essential Oil the Alpinia Zerumbet Associated with Kinesiotherapy on Patient with Muscle Spasticity: Cases Series", International Journal of Research Studies in Biosciences (IJRSB), vol. 5, no. 10, pp. 1-6, 2017. http://dx.doi. org/10.20431/2349-0365.0510001

Copyright: () 2017 Authors. This is an open-access article distributed under the terms of the Creative Commons Attribution License, which permits unrestricted use, distribution, and reproduction in any medium, provided the original author and source are credited. 